\title{
Thymosin B4 expression correlates with lymph node metastasis through hypoxia inducible factor- $\alpha$ induction in breast cancer
}

\author{
SUN YOUNG YOON ${ }^{1}$, HA REUM LEE ${ }^{1}$, YOORIM PARK ${ }^{1}$, JOO HEON KIM ${ }^{2}$, \\ SOO YOUNG KIM ${ }^{3}$, SUK RAN YOON ${ }^{4}$, WANG JAE LEE ${ }^{5}$, BYUNG JOO CHO ${ }^{6}$, HYEYOUNG MIN ${ }^{7}$, \\ JUNG-WOOK BANG ${ }^{10}$, HYUNJEONG PARK $^{8}$, SA IK BANG $^{9}$ and DAEHO CHO ${ }^{1}$
}

${ }^{1}$ Department of Life Science, Sookmyung Women's University, Hyochangwon-gil 52, Yongsan-gu, Seoul 140-742; Departments of ${ }^{2}$ Pathology and ${ }^{3}$ Preventive Medicine, Eulji University, School of Medicine, 143 Yongdu-dong, Jung-gu, Daejeon 301-832; ${ }^{4}$ Stem Cell Center, Korea Institute of Bioscience and Biotechnology (KRIBB), Yusung-Gu, Daejeon 305-333; ${ }^{5}$ Department of Anatomy and Tumor Immunity Medical Research Center, Seoul National University College of Medicine, Seoul; ${ }^{6}$ Department of Ophthalmology, Konkuk University, School of Medicine, Konkuk Univeristy Hospital, Seoul; ${ }^{7}$ College of Pharmacy, Chung-Ang University, Seoul; ${ }^{8}$ Department of Dermatology, St. Mary's Hospital, The Catholic University of Korea, 505 Banpo-dong, Seocho-gu, Seoul 137-701; ${ }^{9}$ Department of Plastic Surgery, School of Medicine, Samsung Medical Center, Sungkyunkwan University, 50 Ilwon-dong, Gangnam-gu, Seoul 135-710, Republic of Korea; ${ }^{10}$ Faculty of Medicine, Imperial College London, London, UK

Received July 1,2010; Accepted August 23, 2010

DOI: $10.3892 /$ or_00001037

\begin{abstract}
Intratumoral hypoxia has been correlated with distant metastatic potential. Two hypoxia inducible factors (HIFs), HIF-1 $\alpha$ and HIF-2 $\alpha$, are induced by hypoxia, and high expression of these proteins has been correlated to angiogenesis and distant metastasis. Thymosin 34 (Tß4) is frequently highly expressed in cancer, and this overexpression correlates with malignant progression. The objective of this study was to investigate the clinical correlation of HIF- $\alpha$ with $\mathrm{T} \beta 4$ and the intracellular functional roles of Tß4 on HIF- $\alpha$ activation. We examined HIF- $1 \alpha$, HIF- $2 \alpha$ and Tß4 expressions in clinical human breast carcinoma $(n=70)$ by immunohisto-
\end{abstract}

Correspondence to: Dr Daeho Cho, Department of Life Science, Sookmyung Women's University, Hyochangwon-gil 52, Yongsan-gu, Seoul 140-742, Republic of Korea

E-mail: cdhkor@sookmyung.ac.kr

Dr Sa Ik Bang, Department of Plastic Surgery, Samsung Medical Center, Sungkyunkwan University School of Medicine, 50 Ilwondong, Gangnam-gu, Seoul 135-710, Republic of Korea

E-mail: sibang55@smc.samsung.co.kr

Abbreviations: Tß4, thymosin 34 ; HIF, hypoxia inducible factor; VEGF, vascular epidermal growth factor; EMT, epithelial-mesenchymal transition; PDGF, platelet-derived growth factor; HGF, hepatocyte growth factor

Key words: thymosin $\beta 4, \mathrm{HIF}-\alpha$, lymph node metastasis, breast carcinoma, VEGF-A chemistry. We show that high expression of HIF-1 $\alpha$ and HIF-2 $\alpha$ strongly correlates with Tß4 expression $(\mathrm{P} \leq 0.0001)$ and overexpression of Tß4 correlates significantly with patients with lymph node metastasis $(\mathrm{P}<0.05)$ of human breast cancer. Additionally, we demonstrate that hypoxia up-regulates intracellular Tß4 protein, which then affects HIF- $\alpha$ activity, which is the key in regulating VEGF expression. We confirmed that hypoxia-induced intracellular Tß4 and HIF- $\alpha$ activities were reduced by interference of Tß4 expression using Tß4 shRNA lentivirus. Vascular epidermal growth factor (VEGF)-A, a well-recognized lymphangiogenic cytokine, was also downregulated, but VEGF-C and VEGF-D expressions were not affected. These findings suggest that the overexpression of Tß4 is strongly associated with HIF- $1 \alpha$ and HIF- $2 \alpha$ expression and is also clinicopathologically involved with lymph node metastatic potential of breast cancer through the modulation of HIF- $\alpha$ activation and induction of VEGF-A. Ultimately, these results highlight $\mathrm{T} B 4$ as a potentially therapeutic target in malignant cancers.

\section{Introduction}

Tumor hypoxia is caused by the unrestricted proliferation of cancer cells, the formation of immature blood vessels and the impairment of microcirculation induced by inflammatory change in tumor tissue (1-3). Prolonged hypoxic conditions induce not only cell death but also genetic and adaptive changes in surviving cells. The surviving cells can adapt to a hypoxic environment through several mechanisms, including angiogenesis (2). Intratumoral hypoxia has been shown to be a prognostic factor in some types of cancer and has been correlated with long distant metastatic potential $(4,5)$. Despite these important clinical observations, the molecular 
basis for tumor hypoxia inducing distant metastasis is not well understood.

Two transcription factors, hypoxia-inducible factor- $1 \alpha$ (HIF- $1 \alpha$ ) and HIF-2 $\alpha$, are dramatically induced by hypoxia and regulate the target genes necessary for tumor adaptation (6). The functional activity of HIF-1 is determined by the levels of HIF-1 $\alpha$ protein expression in the nucleus (7). Under normoxic conditions, HIF- $\alpha$ is rapidly degraded by the ubiquitin-proteasome pathway, whereas under hypoxic conditions the degradation of HIF- $\alpha$ is inhibited (8-11). Increased expression of HIF-1 $\alpha$ protein has been shown during breast carcinogenesis $(12,13)$, and high expression of HIF- $2 \alpha$ has been correlated with angiogenesis, distant tumor recurrence and poor outcome in invasive breast cancer $(14,15)$. Several studies have reported that HIF-1 $\alpha$ expression is associated with unfavorable outcomes in cases of nodepositivity (16) and regulates a spectrum of target genes mainly involved in the modulation of erythropoiesis, angiogenesis, and glucose metabolism (17-19). One of the best characterized genes regulated by HIF- $1 \alpha$ is the gene that encodes VEGF-A, which induces vascular endothelial tip cells to migrate to hypoxic areas and promotes blood vessel growth (16). Six human VEGF-A mRNA species encoding VEGF-A isoforms of $121,145,165,183,189$ and 206 amino acids are produced by alternative splicing. The 121 and 165 amino acid forms are the predominant forms, but expression of the 189 amino acid form can also be seen in most VEGF-producing cell types (20). The VEGF family consists of seven members including: VEGF-A, VEGF-B, VEGF-C, VEGF-D, VEGF-E, VEGF-F and placenta growth factor. Among them, VEGF-C and VEGF-D are well recognized as mediators of lymph node metastasis, and VEGF-A is associated with angiogenesis and lymphangiogenesis in skin tumors and breast cancer $(21,22)$.

Thymosin $\beta 4$ (Tß4) is a small protein that is normally composed of 43-amino acids and is the most abundant member of the $\beta$-thymosins, which are linked to a number of important biological actions, including actin polymerization, angiogenesis, wound healing, inflammation and signaling through the Akt pathway (23-32). Recent studies have shown that Tß4 is frequently overexpressed in malignant tumors and increases tumor growth, metastasis and epithelial-mesenchymal transition (EMT) (33-35). It has also been reported that overexpression of Tß4 is associated with increased invasion and distant metastasis of human colon cancer (34). However, little is known about whether overexpression of Tß4 is related to lymph node metastasis and whether Tß4 can be regulated by hypoxic conditions.

To understand the manner in which hypoxia-induced Tß4 regulates HIF- $\alpha$ activity to induce lymph node metastatic potential, we determined that Tß4 is induced under hypoxic conditions in metastatic breast cancer cells. We also found that down-regulation of HIF- $\alpha$ expression and activation resulted in the inhibition of lymph node metastasis via VEGF-A reduction in Tß4-silenced cells. Our results show that hypoxia-induced Tß4 expression correlates with distant metastasis in human breast carcinoma by inducing increased HIF- $1 \alpha$ and HIF- $2 \alpha$ expression, causing increased expression of VEGF-A.

\section{Materials and methods}

Cell lines and tissue samples. The human breast cancer cells, MDA-MB-231, were purchased from American Type Culture Collection (ATCC, Rockville, MD). Cells were grown in DMEM (Gibco-BRL, Gaithersburg, MA) supplemented with $2 \mathrm{mM}$ L-glutamine, 100 units $/ \mathrm{ml}$ penicillin, $100 \mu \mathrm{g} / \mathrm{ml}$ streptomycin, and 5\% heat-inactivated FBS (Gibco-BRL) in a $5 \% \mathrm{CO}_{2}$ incubator at $37^{\circ} \mathrm{C}$. MDA-MB-231 cells were used for experiments while in the log phase of growth. Human breast carcinoma samples were obtained from patients with breast cancer at the Department of Surgery, Eulji University Hospital (Daejeon, Republic of Korea). For immunohistochemical staining, 70 breast carcinoma and paired normal breast tissues taken from a site distant from the cancerous lesion were fixed in $10 \%$ formalin solution. Each patient's clinical status was classified according to the pathological grade of the tumor size, lymph node, metastasis (pTNM) classification system (36). Histological grade was assessed using the modified Bloom-Richardson classification and nuclear grade was evaluated according to the modified Black's system.

Immunohistochemistry (IHC). Tissue specimens obtained from therapeutic procedures were fixed in neutral buffered formalin (10\% v/v formalin/water, $\mathrm{pH} 7.4)$ and embedded in paraffin wax. Serial sections of $4-\mu \mathrm{m}$ thickness were cut and mounted on charged glass slides (Fisher Scientific, Rochester, NY). IHC for Tß4, HIF-1 $\alpha$, and HIF- $2 \alpha$ in human breast carcinoma tissues was performed in the Dako Techmate 500 system (Dako, Glostrup, Denmark) using anti-Tß4 (1:200; Biodesign International, Saco, ME), anti-HIF-1 $\alpha$ (1:100; Novus Biologicals, Littleton, CO), and anti-HIF-2 $\alpha$ (1:200; Santa Cruz Biotechnology, Santa Cruz, CA). The tissue sections were deparaffined and then treated with $3 \% \mathrm{H}_{2} \mathrm{O}_{2}$ in methanol to quench the endogenous tissue peroxidase activity followed by incubation with $1 \%$ BSA. Antigen retrieval for Tß4, HIF- $1 \alpha$ and HIF- $2 \alpha$ was performed by microwave treatment in citrate buffer $(\mathrm{pH}$ 6.0). The sections were incubated with antibody overnight at $4^{\circ} \mathrm{C}$, and then the sections were stained using a standard EnVision-HRP kit (Dako) for Tß4 and HIF- $2 \alpha$ and Catalysed Signal Amplification System II kit for HIF-1 $\alpha$ (Dako). Finally, peroxidase activity was detected by incubating samples with DAB solution for $3 \mathrm{~min}$. An irrelevant mouse IgG of the same isotype or antibody dilution solution served as a negative control. Immunohistochemical conditions for Tß4, HIF- $1 \alpha$, and HIF- $2 \alpha$ were optimized and evaluated by two independent pathologists (J.H.K. and H.J.S.).

Assessment of immunostaining of T $\beta 4, H I F-1 \alpha$ and HIF-2 $\alpha$. Each slide was evaluated for T $\beta 4$, HIF- $1 \alpha$, and HIF- $2 \alpha$ immunoreactivity using a semi-quantitative scoring system for both the intensity of the stain and the percentage of positive neoplastic cells, and tumors were graded by four degrees of severity. The percentage of cells displaying a stronger staining intensity than the adjacent ductal epithelium was graded as G1 (0-24\% tumor cells stained); G2 (25-49\% tumor cells stained); G3 (50-74\% tumor cells stained); or G4 (75-100\% tumor cells stained). For the purpose of statistical 
analysis, the median of this series (25\% of malignant cells showing a stronger intensity than adjacent ductal epithelium) was used as a cut-off value to distinguish tumors with low $(<25 \%)$ or high $(>25 \%)$ levels of Tß4, HIF-1 $\alpha$, and HIF- $2 \alpha$ expressions.

Flow cytometry for Tß4 expression. After incubation under hypoxic conditions, MDA-MB-231 cells were washed in PBS and centrifuged. The cells were fixed with $4 \%$ paraformaldehyde (Sigma, St. Louis, MO) and permeabilized with $0.1 \%$ saponin (Sigma). Rabbit polyclonal $(10 \mu \mathrm{g})$ anti-human Tß4 antibody was added to each tube and incubated for $1 \mathrm{~h}$ on ice. Anti-rabbit IgG (H+L)-FITC conjugated antibody was then added and samples were incubated for $30 \mathrm{~min}$ on ice and then washed with PBS. Supernatant was removed and the cells were resuspended in $250 \mu 1$ of PBS for flow cytometry (FACSCalibur, BD, Franklin Lakes, NJ).

Lenti-Tß4 shRNA vector and Lenti-Tß4 shRNA viruses. For shRNA-mediated knockdown, we employed an Expression Arrest $^{\mathrm{TM}}$ GIPZ lentiviral shRNAmir system (Open Biosystems, Huntsville, AL) (37). The scramble shRNA control vector and an shRNA knockdown pGIPZ plasmid against the Tß4 gene were purchased from Open Biosystems. The target sequences are listed below. The three-component plasmid system, including a transfer vector, a VSV-G expression vector, and a gag-pol expression vector, was used to produce replication-incompetent high-titer lentiviruses that expressed the shRNA constructs using Lipofectamine 2000 (Invitrogen, Carlsbad, CA) transfectant reagent in HEK 293T cells following the established protocols as described $(38,39)$. The Tß4 specific shRNA construct sequence was: (TGCTG TTGACAGTGAGCGCGCAAAGAGGTTGGATCAAG TTTAGTGAAGCCACAGATGTAAACTTGATCCAAC CTCTTTGCATGCCTACTGCCTCGGA). The high-titer lenivirus carrying shRNA knockdown construct was generated, and virus titers were determined by immunoblotting viral lysates using anti-HIV capsid protein p24 antibody or a p24 ELISA kit (39). The lentiviruses expressing Tß4 shRNA were used to infect human breast cancer cells to knock down Tß4 mRNA expression. The lentiviruses expressing scramble shRNA construct were used to infect as a control. Successful Tß4 mRNA transcript knockdown was confirmed by RT-PCR.

$R T$-PCR. Total RNA was isolated using TRIzol ${ }^{\circledR}$ reagent (Invitrogen), and cDNA was synthesized using M-MLV reverse transcriptase (Promega, Madison, WI). Two micrograms of total RNA was diluted in $15 \mu \mathrm{l}$ of distilled water, and oligo (dT) primer was added. The primed RNA was reverse transcribed for $1 \mathrm{~h}$ at $42^{\circ} \mathrm{C}$ in reaction buffer [5 $\mu 1$ of M-MLV RT 5X Buffer, $1 \mu 1$ of $5 \mathrm{U} / \mu 1$ ribonuclease inhibitor (Promega), $2 \mu 1$ of $25 \mathrm{mM}$ dNTP (Takara, Shiga, Japan), and $1 \mu \mathrm{l}$ of M-MLV reverse transcriptase]. One microliter of the synthesized cDNA was used for each $20 \mu 1$ PCR reaction with 2X PCR Master mix Solution (iNtRON Biotechnology, SungNam, South Korea), and was amplified under the following thermocycling conditions; $94^{\circ} \mathrm{C}$ for $5 \mathrm{~min}$, then $25-30$ cycles of $94^{\circ} \mathrm{C}$ for $30 \mathrm{sec}, 60^{\circ} \mathrm{C}$ for $30 \mathrm{sec}$ and $72^{\circ} \mathrm{C}$ for $1 \mathrm{~min}$, followed by a final extension of $7 \mathrm{~min}$ at $72^{\circ} \mathrm{C}$ using Takara PCR Thermal Cycler Dice system (Takara). For the PCR reactions, the following primer sets were used: human Tß4, sense, 5'-ACA AAC CCG ATA TGG CTG AG-3' and antisense, 5'-TGC TTG CTT CTC CTG TTC AA-3'; ß-actin, sense, 5'-TCA CCC ACA CTG TGC CCA TCT ACG-3' and antisense, 5'-CAG CGG AAC CGC TCA TTG CCA ATG-3'; VEGF, sense, 5'-CCA TGA ACT TTC TGC TGT CTT GG-3' and antisense, 5'-CTC ACC GCC TCG GCT TGT CAC-3'; VEGF-A $_{189}$, sense, 5'-GTA TAA GTC CTG GAG CGT-3' and antisense, 5'-TGT CCC TGG AAG AAC ACA GCC-3'; VEGF-A $_{121-165}$, sense, 5'-GTG AAT GCA GAC CAA AGA AAG-3' and antisense, 5'-AAA CCC TGA GGG AGG CTC-3'; VEGF-C, sense, 5'-GTC TGT GTC CAG TGT AGA TG-3' and antisense, 5'-TAC GAG GTG CTG GTG TTC ATA C-3'; HIF-1 $\alpha$, sense, 5'-CAA AAC ACA CAG CGA AGC-3' and antisense, 5'-TCA ACC CAG A TAT CCA CC-3'; HIF-2 $\alpha$, sense, 5'-AGC CTC CAT CTG CCA TCA GTC-3' and antisense, 5'-CTT GCC ATG CCT GAC ACC TTG-3'. The PCR products were separated on $2 \%$ agarose gel, stained with ethidium bromide, visualized by Gel Doc System (Uvitec, Cambridge, UK), and analyzed using TL100 software (Nonlinear Dynamics Ltd., Newcastle, UK).

ELISA. Culture supernatants from Tß4 shRNA or scramble lentivirus transduced MDA-MB-231 cells were collected at 24, 48 and $72 \mathrm{~h}$. Concentrations of VEGF in these supernatants were quantified using a Quantikine ${ }^{\circledR}$ human VEGF immunoassay (R\&D Systems, Inc., Minneapolis, MN) according to the manufacturer's instructions.

Western blot analysis. Total cell lysates from control $\left(1 \times 10^{6}\right.$ cells) or Tß4 shRNA transfected MDA-MB-231 cells $\left(1 \times 10^{6}\right.$ cells) were prepared in 1X SDS-lysis buffer [60 mM Tris$\mathrm{HCl}$ (pH 6.8), 5\% glycerol, 0.5\% SDS, $2.8 \mathrm{mM}$ 2-mercaptoethanol, and $0.02 \%$ bromophenol blue] with boiling. Cell lysates were resolved by SDS-PAGE on $6 \%$ or $12 \%$ gels and transferred to PVDF membranes (Bio-Rad Laboratories, Hercules, CA). The membranes were incubated with primary antibodies followed by peroxidase-conjugated goat antirabbit or anti-mouse IgG secondary antibodies (Jackson ImmunoResearch Laboratory Inc., West Grove, PA) and ECL reagent (Amersharm Biosciences Inc., Piscataway, NJ) for band visualization. To verify equal loading, anti- $\gamma$-tubulin antibody (Santa Cruz Biotechnology) was used. The primary antibodies were anti-HIF- $1 \alpha$ (Novus Biologicals) and antiHIF-2 $\alpha$ (Novus Biologicals).

Transient transfection and luciferase assay. Scrambledor Tß4-shRNA transfected MDA-MB-231 cells at $~ 50 \%$ confluence in 6-well plates were transfected with reporter luciferase plasmid, pGL3-HRE, using Lipofectamin 2000 (Invitrogen) in accordance with the manufacturer's instructions. After incubation (36 h), the cells were harvested and luciferase activity was measured using a luciferase assay kit (Promega). All experiments were conducted in triplicate, and luciferase activity was normalized to $\beta$-galactosidase activity.

Statistical analysis. Experimental differences were determined using a Student's t-test. The relationship between the results 

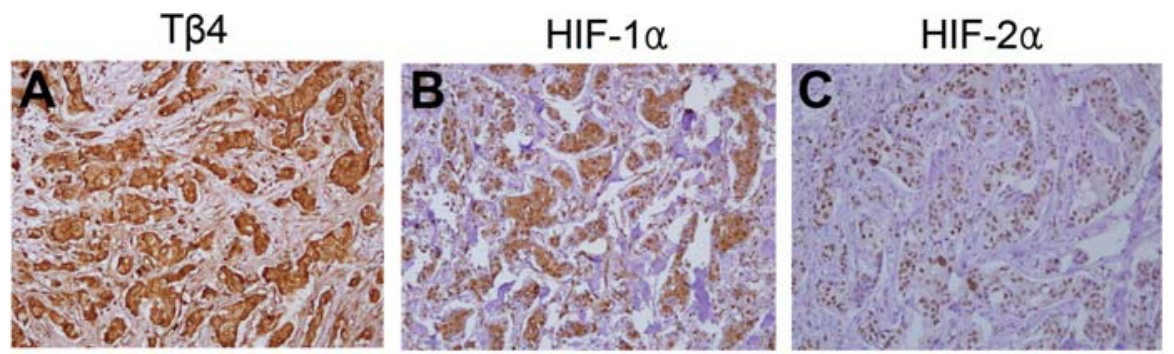

Figure 1. Tß4, HIF-1 $\alpha$ and HIF-2 $\alpha$ expression in human breast carcinoma. Immunohistochemical staining of breast tumor tissues with anti-Tß4 (A), anti-HIF-1 $\alpha$ (B) or anti-HIF-2 $\alpha$ (C) antibodies. (A) TB4 is highly expressed and is mostly localized in the cytosol of tumor cells. (B) HIF-1 $\alpha$ is highly expressed in both the nucleus and cytosol of tumor cells. (C) HIF-2 $\alpha$ is also highly expressed in tumor cells and is mostly localized in the nucleus of cells. $\mathrm{N}$ and T represent normal and tumor tissue, respectively. (A, B and C, x40 magnification).
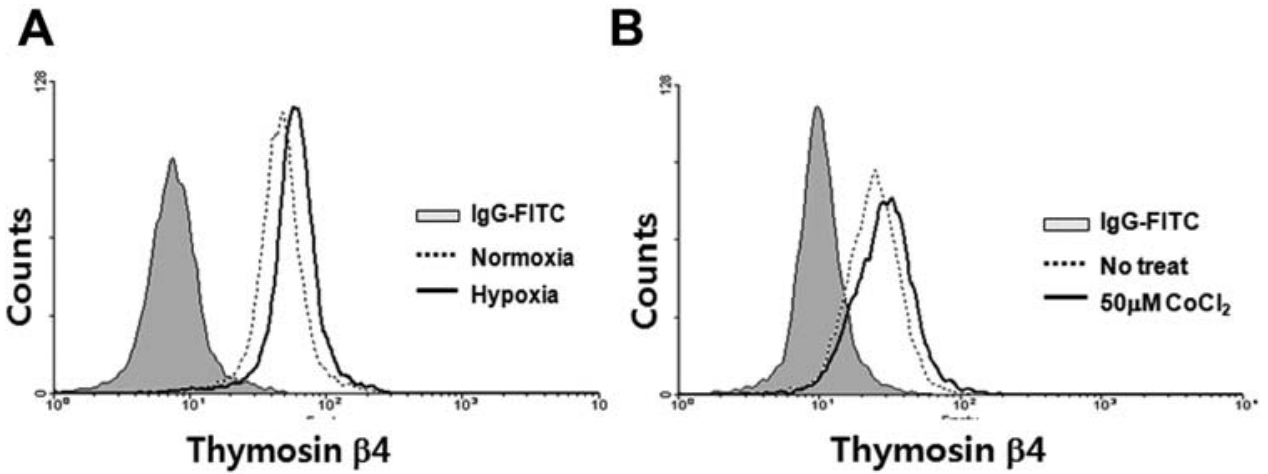

Figure 2. Tß4 expression is induced by hypoxia. Human breast cancer cell line MDA-MB-231 was exposed to hypoxia $\left(1 \%\right.$ oxygen, or $\left.50 \mu \mathrm{M} \mathrm{CoCl} \mathrm{l}_{2}\right)$ or normoxia for $24 \mathrm{~h}$. (A) MDA-MB-231 cells exposed to hypoxia ( $1 \%$ oxygen) or normoxia were fixed with $4 \%$ paraformaldehyde and permeabilized with $0.1 \%$ saponin for intracellular TB4 staining. Grey area shows control cells, dotted line represents cells under normoxia and bold line shows hypoxia-stimulated cells. (B) Chemical hypoxic-inducing condition $\left(50 \mu \mathrm{M} \mathrm{CoCl}_{2}\right)$ is often used to mimic hypoxia. MDA-MB-231 cells treated with or without $50 \mu \mathrm{M} \mathrm{CoCl} 2$ were stained with Tß4 antibodies for FACs analysis.

Table I. Relationship between Tß4 expression and HIF-1 $\alpha /$ HIF- $2 \alpha$.

\begin{tabular}{|c|c|c|c|c|}
\hline Variables & $\begin{array}{c}\text { Negative } \\
(\%)\end{array}$ & $\begin{array}{c}\text { Low } \\
\text { positive } \\
(\%)\end{array}$ & $\begin{array}{c}\text { High } \\
\text { positive } \\
(\%)\end{array}$ & P-value \\
\hline $\mathrm{HIF}-1 \alpha$ & & & & 0.0001 \\
\hline Negative (\%) & $19(59)$ & $3(9)$ & $10(31)$ & \\
\hline Low positive (\%) & $0(0)$ & $5(42)$ & $7(58)$ & \\
\hline High positive (\%) & $5(19)$ & $0(0)$ & $21(81)$ & \\
\hline HIF- $2 \alpha$ & & & & $<0.0001$ \\
\hline Negative (\%) & $18(72)$ & $0(0)$ & $7(28)$ & \\
\hline Low positive (\%) & $2(10)$ & $6(32)$ & $11(58)$ & \\
\hline High positive (\%) & $4(15)$ & $2(8)$ & $20(77)$ & \\
\hline
\end{tabular}

of the immunohistochemical study and the clinicopathological parameters was determined using SASR software package (version 8.01; SAS Institute, Cary, NC). Univariate and multivariate analyses were carried out using the proc logistic module. In all cases, the exact mid-P adjusted P-values were reported and a $\mathrm{P}$-value $<0.05$ was considered to be statistically significant.

\section{Results}

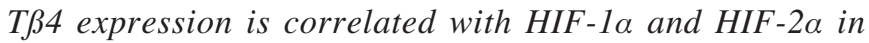
breast carcinoma. It has been reported that Tß4 induces HIF- $1 \alpha$ stabilization and activity (40). To explore the correlation of Tß4 expression with expression of two HIF- $\alpha$ subunits, HIF- $1 \alpha$ and HIF-2 $\alpha$, we first screened for T $\beta 4$, HIF- $1 \alpha$, and HIF- $2 \alpha$ expression in 70 human breast cancer tissues by IHC. Immunostaining showed high levels of Tß4 in the cytoplasm of tumor cells, while the matching normal tissues displayed comparably weak expression of Tß4 (Fig. 1A). HIF-1 $\alpha$ and HIF-2 $\alpha$ expression were highly expressed in the cell nuclei in breast tumor sections (Fig. 1B and C), and HIF-1 $\alpha$ was also expressed in cytoplasm of tumor cells (Fig. 1B). To determine if there was an association between Tß4 and HIF- $1 \alpha$ or HIF- $2 \alpha$ expression in human breast carcinoma, we compared Tß3 expression levels with HIF- $1 \alpha$ and HIF- $2 \alpha$ levels (Table I). We found a statistically significant correlation between Tß4 expression and HIF-1 $\alpha$ $(\mathrm{P}=0.0001)$ as well as between Tß4 and HIF-2 $\alpha(\mathrm{P}<0.0001)$.

Relationship between Tß4 and clinicopathological findings. We next analyzed associations between Tß4 expression and patient age, histological grade, tumor size, estrogen receptor, progesterone receptor, c-erbB2, or p53 expressions (Table II). Multivariate analysis showed a significant association 
Table II. Tß4 expression in human breast carcinoma in relation to clinicopathological parameters.

\begin{tabular}{|c|c|c|c|c|}
\hline \multicolumn{5}{|c|}{ Results of univariate analysis with $\mathrm{T} \beta 4$ expression } \\
\hline Variables & $\begin{array}{c}\text { Negative } \\
(\%)\end{array}$ & $\begin{array}{c}\text { Low } \\
\text { positive } \\
(\%)\end{array}$ & $\begin{array}{c}\text { High } \\
\text { positive } \\
(\%)\end{array}$ & P-value \\
\hline Age (years) & & & & $\mathrm{NS}^{\mathrm{a}}$ \\
\hline$<50$ & $11(30)$ & $5(13)$ & $21(57)$ & \\
\hline$\geq 50$ & $13(39)$ & $3(9)$ & $17(52)$ & \\
\hline Histological grade (HG) & & & & NS \\
\hline I & $7(35)$ & $4(20)$ & $9(45)$ & \\
\hline II & $14(33)$ & $4(9)$ & $25(58)$ & \\
\hline III & $3(43)$ & $0(0)$ & $4(57)$ & \\
\hline Tumor size $(\mathrm{cm})$ & & & & NS \\
\hline$<2$ in diameter & $14(41)$ & $6(18)$ & $14(41)$ & \\
\hline $2-5$ in diameter & $8(27)$ & $1(3)$ & $21(70)$ & \\
\hline$>5$ in diameter & $2(33)$ & $1(17)$ & $3(50)$ & \\
\hline Lymph node metastasis & & & & 0.0203 \\
\hline $\mathrm{N}_{0}$ & $17(50)$ & $4(12)$ & $13(38)$ & \\
\hline $\mathrm{N}_{1}$ & 7 (19) & $4(11)$ & $25(69)$ & \\
\hline Estrogen receptor & & & & NS \\
\hline Negative & $14(38)$ & $3(8)$ & $20(54)$ & \\
\hline Positive & $10(30)$ & $5(15)$ & $18(55)$ & \\
\hline Progesteron receptor & & & & NS \\
\hline Negative & $18(43)$ & $3(7)$ & $21(50)$ & \\
\hline Positive & $6(21)$ & $5(18)$ & $17(61)$ & \\
\hline c-erbB2 & & & & NS \\
\hline Negative & $19(40)$ & $4(9)$ & $24(51)$ & \\
\hline Positive & $5(22)$ & $4(17)$ & $14(61)$ & \\
\hline p53 & & & & NS \\
\hline Negative & $19(37)$ & $7(13)$ & $26(50)$ & \\
\hline Positive & $5(28)$ & $1(5)$ & $12(67)$ & \\
\hline
\end{tabular}

${ }^{\mathrm{a} N S}$, non-significant.

Table III. Results of multivariate logistic regression analysis with Tß4 expression.

\begin{tabular}{|c|c|c|c|}
\hline Categories & $\mathrm{P}$-value & Odds ratio & $95 \%$ Confidence limits \\
\hline Nodal status & 0.0192 & 7.9055 & $0.056-0.573$ \\
\hline
\end{tabular}

between Tß4 and nodal status ( $\mathrm{P}=0.0192$, Table III). Several previous reports have shown that HIF- $\alpha$ correlates with metastasis and distant recurrence (12-15) and also correlates with VEGF-C expression and lymphangiogenesis in breast cancer (41). Therefore, we hypothesize that Tß4 may help regulate the process of lymph node metastasis due to its strong correlation with HIF- $\alpha$ expression.
Tß4 expression is induced under hypoxic conditions. To elucidate the functions of Tß4 under hypoxic conditions, we determined whether TB4 expression is regulated by hypoxia, a critical factor for inducing HIF- $\alpha$ expression. MDA-MB-231 cells were exposed to hypoxic $\left(1 \% \mathrm{O}_{2}\right.$ or $\left.50 \mu \mathrm{M} \mathrm{CoCl}_{2}\right)$ or normoxic conditions for $24 \mathrm{~h}$. Intracellular Tß4 protein was dramatically increased under hypoxic conditions (Fig. 2). Additionally, the secretion of Tß4 from cells under hypoxic conditions was not detected (data not shown). Collectively, these results demonstrate that hypoxia induces the expression of intracellular Tß4.

Inhibition of T $\beta 4$ by shRNA reduced HIF-1 $\alpha$ and HIF-2 $\alpha$ expression and activity. To elucidate the functional roles of intracellular Tß4 on HIF- $\alpha$ expression or activation, we interfered with Tß4 expression by introduction of Tß4 shRNA lentivirus to MDA-MB-231 cells. Tß4 down-regulation by introduction of shRNA lentiviruses decreased HIF- $1 \alpha$ and HIF- $2 \alpha$ mRNA expression (Fig. 3A and B), but did not regulate HIF-1ß mRNA level (data not shown). The protein levels of HIF- $1 \alpha$ and HIF-2 $\alpha$ in Tß4 shRNA transfected cells were reduced (Fig. 3C and D). Coincidently, HIF- $\alpha$ activity was also down-regulated with an HRE-luciferase reporter construct (Fig. 3E). These results indicate that intracellular Tß4 expression is closely associated with HIF- $\alpha$ expression and activation.

Inhibition of Tß3 expression by shRNA reduced levels of $V E G F$ mRNA and secretion. In previous data, we showed that Tß4 expression correlated significantly with lymph node metastasis in human breast carcinoma (Tables II and III). Lymphangiogenic growth factors that promote formation of tumor lymphatics and metastatic spread of tumor cells to lymph nodes have been identified (42) and include secreted VEGF-A, VEGF-C and VEGF-D, which are all main target genes of HIF- $\alpha(42,43)$. To confirm that T $\beta 4$ can regulate expression of these VEGF isoforms, we prepared MDA-MB231 cells with silenced TB4 expression by shRNA lentivirus and analyzed the levels of VEGF mRNA (Fig. 4A) and protein production (Fig. 4B). When Tß4 expression was blocked via shRNA lentivirus transduction for $24 \mathrm{~h}$, Tß4 mRNA expression was reduced by $70 \%$ and VEGF mRNA expression was also down-regulated in MDA-MB-231 cells. Secretion of VEGF protein from MDA-MB-231 cells was inhibited by Tß4 down-regulation for 24, 48 and $72 \mathrm{~h}$.

VEGF-A was down-regulated by Tß4 shRNA transfection but other isoforms of VEGF family were not affected. It is well known that VEGF-A, VEGF-C and VEGF-D are mediators of lymph node metastasis (42). To determine whether Tß4 expression regulates any of the isoforms of the VEGF family,

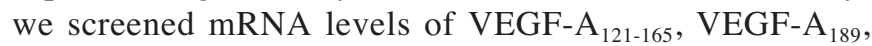
VEGF-C and VEGF-D in Tß4 down-regulated cells (Fig. 4C and D). We found that down-regulation of Tß4 expression reduced VEGF-A expression by $50-60 \%$ but did not affect the other isoforms. VEGF-D expression was not detected in MDAMB-231 cells (data not shown). Also, it has been shown that soluble TB4 peptide plays a role in HIF-1 $\alpha$ stabilization and increase of VEGF mRNA expression in cervical cancer cells (40). To define the effects of soluble Tß4 peptide treatment 
A

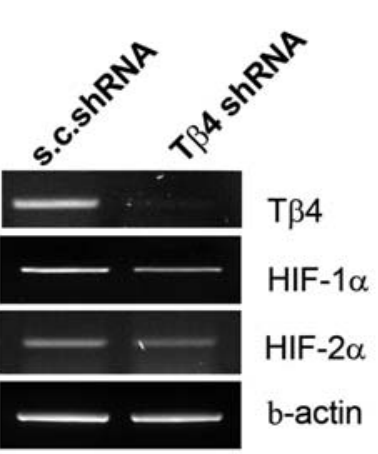

C

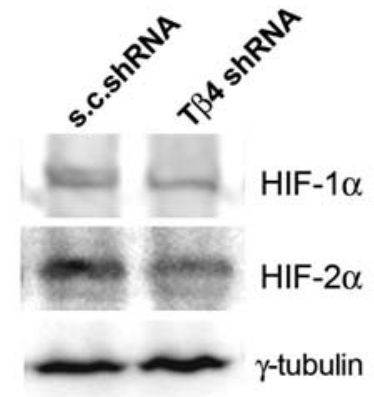

B
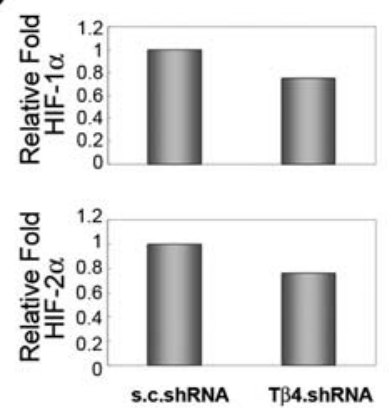

D

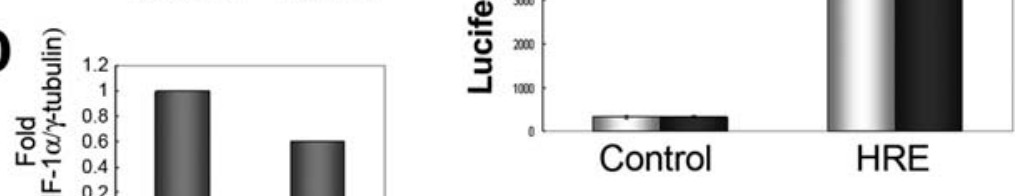

$\mathrm{E}$

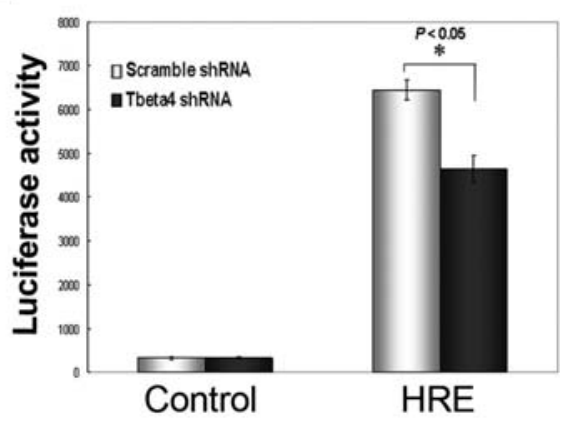

Figure 3. Down-regulation of HIF- $1 \alpha / 2 \alpha$ expression and activity following Tß4 shRNA transfection. (A) HIF- $1 \alpha / 2 \alpha$ mRNA expression was reduced by knockdown of Tß4 expression in MDA-MB-231 cells, but HIF-1 $\alpha$ mRNA expression was not. (B) Relative values of HIF-1 $\alpha$ and HIF-2 $\alpha$ are represented as described above in A. (C) Protein expression levels of HIF-1 $\alpha / 2 \alpha$ were decreased following Tß4 shRNA introduction to MDA-MB-231 cells. (D) Relative values of C. (E) HIF- $\alpha$ activity was measured using transient transfection with HRE reporter plasmid. The results show that TB4 down-regulation by shRNA transfection reduced HIF- $\alpha$ promoter activity.

A

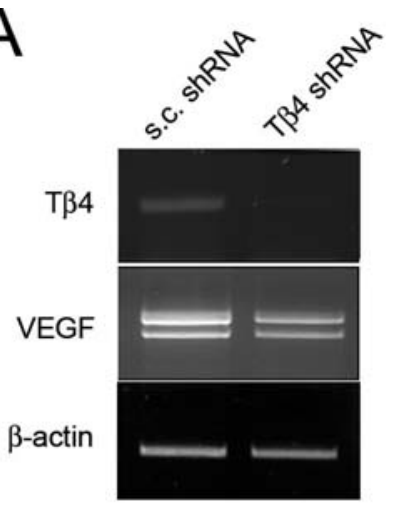

B

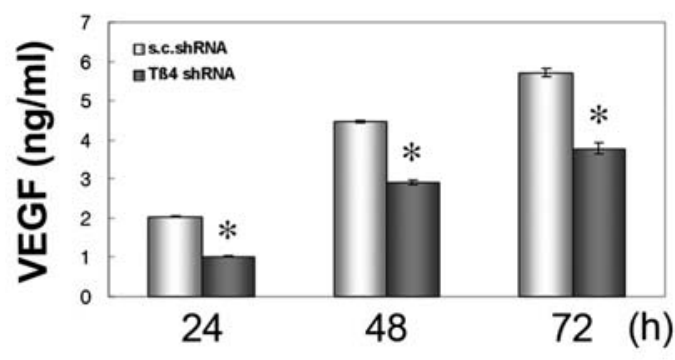

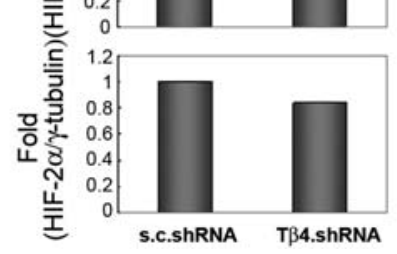
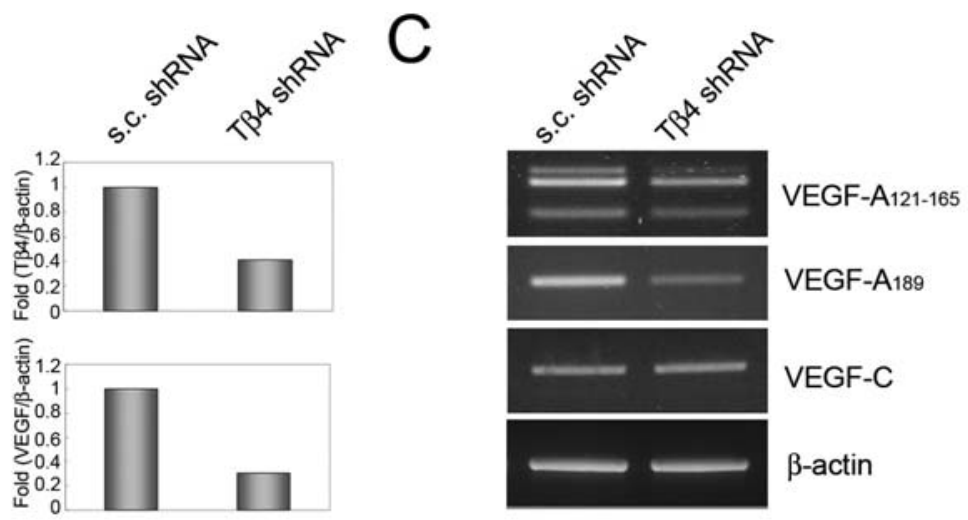
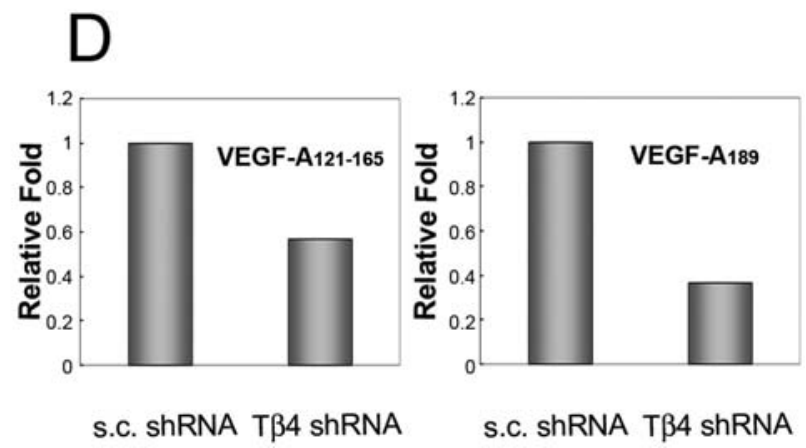

s.c. ShRNA TB4 shRNA

Figure 4. Down-regulation of VEGF expression by Tß4 shRNA treatment. (A) In left panel, reduced Tß4 and VEGF mRNA expression following transduction of Tß4 shRNA lentivirus for $24 \mathrm{~h}$ was confirmed in breast cancer cell line, MDA-MD-231, by RT-PCR analysis. Scramble (s.c.) shRNA lentivirus was used as a control for viral transfection. In right panel, relative fold change of Tß4 and VEGF expression was analyzed as described above. (B) VEGF secretion was inhibited by TB4 shRNA treatment in MDA-MB-231 cells. TB4 shRNA transfected MDA-MB-231 cells showed reduced VEGF production compared with control (s.c.shRNA transfected) cells. *Represents P-value <0.05. (C) Reduction of VEGF-A mRNA expression following Tß4 shRNA treatment. VEGF-C expression was not affected. Expression of VEGF isoforms including VEGF-A (VEGF-A 121-165 and VEGF-A ${ }_{189}$ ) and VEGF-C was analyzed in Tß4 shRNA transfected MDA-MB-231 cells by RT-PCR and compared to control cells. (D) The lower panel shows relative fold change of VEGF-A $\mathrm{A}_{121-165}$ and VEGF-A ${ }_{189}$ expression relative to $B$-actin, performed as described above. 
on VEGF isoform expression, we determined the mRNA levels of VEGF isoforms in MDA-MB-231 cells treated with $1 \mu \mathrm{g} / \mathrm{ml}$ or $4 \mu \mathrm{g} / \mathrm{ml} \mathrm{TB} 4$ (data not shown). Unlike the modulation of endogenous TB4 expression, introduction of exogenous Tß4 peptide to the cells had no effect on regulation of VEGF-A, VEGF-C and VEGF-D mRNA and protein production (data not shown). These results demonstrate that the inhibition of intracellular Tß4 expression results in the down-regulation of VEGF-A production, ultimately leading to lymphangiogenesis.

\section{Discussion}

Tumor hypoxia is a prominent feature of malignant tumors and correlates with distant metastatic potential $(4,5)$. These prolonged hypoxic conditions make the tumors more difficult to treat and confer increased resistance to death from chemotherapy and radiotherapy (44). Tumor cells must survive by adapting to the low $\mathrm{pO}_{2}$, by increasing vascularization, or both. Many gene products are involved in angiogenesis in tumors, and one of the most investigated targets is VEGF, which is secreted by hypoxic tumor cells. Many of these hypoxia-regulated genes, including those for VEGF, are mediated by HIF complex, which is therefore a pivotal gene in the cancer biology of hypoxic adaptation and angiogenesis. Interestingly, a recent report shows that Tß4 stabilizes HIF-1 $\alpha$ in human cervical cancer cells (40). Based on this, we evaluated the functional roles of Tß4 under hypoxia in breast cancer by studying the correlation between clinical observations and cellular roles of Tß4.

In the present study, we have demonstrated that Tß4 expression significantly correlates with lymph node metastasis in breast carcinoma (Tables II and III) and is also highly associated with both HIF- $1 \alpha$ and HIF- $2 \alpha$, which are indicators of hypoxic condition (Table I). Next, we determined that Tß4 is induced by hypoxia, which then regulates HIF- $\alpha$ expression and increases production of VEGF. Tß4 overexpression was significantly correlated with lymph node metastasis $(\mathrm{P}=0.0203)$, but not with several other clinicopathological parameters including age, histological grade, tumor size, estrogen receptor, progesterone receptor, c-erbB2, and p53 in human breast carcinoma, which is similar to the correlation found in a previous report on colon cancer (34). However, there is also a controversial report showing that Tß4 was down-regulated in metastatic cells from colorectal carcinomas (45). Additionally, another report has shown the important role of local expression of Tß4 peptide in the tumor microenvironment but not in tumor cells to regulate tumor behavior (46). However, our results indicate that Tß4 is more abundant in tumor cells compared with the corresponding non-tumor cells, and overexpression of Tß4 in tumor cells was strongly related with lymph node metastasis, but not other clinicopathological parameters in human breast carcinoma. Based on these findings, we also evaluated the roles of Tß4 in lymph node metastasis in breast carcinoma.

Based on a report that T 34 proteins affect HIF- $1 \alpha$ stabilization (40), we investigated whether increased Tß4 expression correlates with HIF- $1 \alpha$ or HIF- $2 \alpha$ expression levels under hypoxic conditions, which are known to induce Tß4 production. We demonstrated that hypoxic conditions dramatically up-regulated the intracellular Tß4 expression in MCF7 (data not shown) and MDA-MB231 cells (Fig. 2). From these data, we conclude that tumor hypoxia stimulates the tumor cells to increase intracellular T 34 and lead to HIF- $\alpha$ activation. This indicates that Tß4 could be a mediator of HIF- $\alpha$ activation by hypoxia. We have also shown that high levels of HIF- $1 \alpha$ or HIF- $2 \alpha$ in breast tumor cells are significantly related to overexpression of Tß4 proteins (Table I). It has been reported that HIF-1 $\alpha$ is closely linked to aggressive phenotypes such as tumor size, lymph node metastasis, tumor stage, histological grade, HER2 expression, increased VEGF, COX-2 overexpression and increased nuclear p53 in invasive breast cancer (13), and is also correlated with VEGF-C expression and lymphangiogenesis in breast cancer (41). Recently, HIF-2 $\alpha$ expression was shown to be an independent prognostic factor associated with distant recurrence and poor outcome, whereas HIF-1 $\alpha$ did not exhibit these correlations in invasive breast cancer (15). Until now, it has not been well elucidated whether HIF- $1 \alpha$, HIF- $2 \alpha$ and Tß4 expressions in breast carcinoma tissues is significantly correlated. Additionally, the down-regulation of Tß4 induced reduction of HIF- $1 \alpha$ and HIF- $2 \alpha$ mRNA and protein expression as shown by the decrease of HRE promoter activity (Fig. 3). Our data are the first to show that down-regulated intracellular Tß4 affects the regulation of HIF- $1 \alpha$ and HIF- $2 \alpha$ expression in breast cancer cells. Therefore, we investigated this further to reveal how Tß4 directly regulates the expression of HIF- $\alpha$ and which signaling pathway is involved in this regulation.

Generally, lymph node metastasis is the main indicating factor in many malignancies, including breast carcinomas. Mediators of lymph node metastasis in several types of cancer include VEGF-C, VEGF-D, VEGF-A, platelet-derived growth factor (PDGF)-BB, and hepatocyte growth factor (HGF) $(42,43,47-49)$. It is well known that increase of Tß4 is involved in angiogenesis and induces VEGF production (26). However, the specific isoforms of VEGF affected by Tß4 stimulation is still unknown. We confirmed that Tß4 regulates only the expressions of VEGF-A but not the other isoforms (Fig. 4). VEGF-A is one of the best characterized genes increased by HIF, and it has been shown that VEGF-Aoverexpressing primary skin tumors in mice induce lymphangiogenesis in sentinel lymph nodes before arrival of metastatic tumor cells, indicating that sentinel lymph node lymphangiogenesis may be connected with metastasis to other organs (21). In some studies, lymphangiogenesis in the nodal metastases is a stronger prognostic indicator than analyses of primary tumors in breast cancer (50). These data imply that hypoxia-induced $\mathrm{T} \beta 4$ could regulate the expression of VEGF-A which may use expressing cells to promote lymphangiogenesis involved with lymph node or distant metastasis.

Additionally, secreted Tß4 polypeptide in tumor tissues was closely involved with tumor malignancy and metastasis (25). Therefore, we investigated the regulation of expression of VEGF isoforms by introduction of extrinsic Tß4 polypetide to breast cancer cells. Interestingly, treatment with Tß4 peptide did not significantly affect the modulation of VEGF mRNA or VEGF secretion from Tß4 peptide-treated cells (data not shown). At low levels of Tß4 treatment (10-100 ng/ml), there was no difference in the mRNA expression levels of 
VEGF isoforms (data not shown). ELISA did not detect secreted Tß4 derived from cultured breast cancer cells, which is consistent with a previous report that described no detection of secreted Tß4 from Tß4 adenovirus-infected B16F10 cells (25). From these data, we conclude that the modulation of intracellular Tß4 expression is mainly involved in the regulation of VEGF-A expression.

In conclusion, our data suggest that hypoxia-induced Tß4 is strongly associated with HIF- $1 \alpha$ and HIF- $2 \alpha$ expression and is also clinicopathologically involved with lymph node metastatic potential of breast cancer by modulating HIF- $\alpha$ activation and induction of VEGF-A in breast cancer cells. Ultimately, these results warrant further investigation of Tß4 as a potential therapeutic target in malignant cancers.

\section{Acknowledgements}

This study was supported by the Korea Research Foundation Grant funded by the Korean Government [MOEHRD, Basic Research Promotion Fund (KRF-2008-314-E00092)], the SRC program (Research Center for Women's Diseases, R11-2005-017) of Korea Science \& Engineering Foundation (KOSEF) and Seoul Research and Business Development Program (10582).

\section{References}

1. Vaupel P, Kallinowski F and Okunieff P: Blood flow, oxygen and nutrient supply, and metabolic microenvironment of human tumors: a review. Cancer Res 49: 6449-6465, 1989.

2. Semenza GL and Wang GL: A nuclear factor induced by hypoxia via de novo protein synthesis binds to the human erythropoietin gene enhancer at a site required for transcriptional activation. Mol Cell Biol 12: 5447-5454, 1992.

3. Hockel M and Vaupel P: Tumor hypoxia: definitions and current clinical, biologic, and molecular aspects. J Natl Cancer Inst 93: 266-276, 2001.

4. Hockel M, Schlenger K, Aral B, Mitze M, Schaffer U and Vaupel P: Association between tumor hypoxia and malignant progression in advanced cancer of the uterine cervix. Cancer Res 56: 4509-4515, 1996.

5. Hockel M, Schlenger K, Hockel S and Vaupel P: Hypoxic cervical cancers with low apoptotic index are highly aggressive. Cancer Res 59: 4525-4528, 1999.

6. Wang GL, Jiang BH, Rue EA and Semenza GL: Hypoxiainducible factor 1 is a basic-helix-loop-helix-PAS heterodimer regulated by cellular O2 tension. Proc Natl Acad Sci USA 92: 5510-5514, 1995.

7. Semenza GL: Regulation of mammalian $\mathrm{O} 2$ homeostasis by hypoxia-inducible factor 1. Annu Rev Cell Dev Biol 15: 551-578, 1999.

8. Brahimi-Horn MC and Pouyssegur J: HIF at a glance. J Cell Sci 122: 1055-1057, 2009.

9. Schofield CJ and Ratcliffe PJ: Oxygen sensing by HIF hydroxylases. Nat Rev Mol Cell Biol 5: 343-354, 2004.

10. Salceda $\mathrm{S}$ and Caro J: Hypoxia-inducible factor 1alpha (HIF-1 alpha) protein is rapidly degraded by the ubiquitinproteasome system under normoxic conditions. Its stabilization by hypoxia depends on redox-induced changes. J Biol Chem 272: 22642-22647, 1997.

11. Huang LE, Gu J, Schau M and Bunn HF: Regulation of hypoxiainducible factor 1 alpha is mediated by an O2-dependent degradation domain via the ubiquitin-proteasome pathway. Proc Natl Acad Sci USA 95: 7987-7992, 1998.

12. Liao D, Corle C, Seagroves TN and Johnson RS: Hypoxiainducible factor-1alpha is a key regulator of metastasis in a transgenic model of cancer initiation and progression. Cancer Res 67: 563-572, 2007.

13. Yamamoto Y, Ibusuki M, Okumura Y, et al: Hypoxia-inducible factor 1alpha is closely linked to an aggressive phenotype in breast cancer. Breast Cancer Res Treat 110: 465-475, 2008.
14. Giatromanolaki A, Sivridis E, Fiska A and Koukourakis MI: Hypoxia-inducible factor-2 alpha (HIF-2 alpha) induces angiogenesis in breast carcinomas. Appl Immunohistochem Mol Morphol 14: 78-82, 2006.

15. Helczynska K, Larsson AM, Holmquist Mengelbier L, et al: Hypoxia-inducible factor-2alpha correlates to distant recurrence and poor outcome in invasive breast cancer. Cancer Res 68: 9212-9220, 2008.

16. Semenza GL: Targeting HIF-1 for cancer therapy. Nat Rev Cancer 3: 721-732, 2003.

17. Harris AL: Hypoxia, a key regulatory factor in tumour growth. Nat Rev Cancer 2: 38-47, 2002.

18. Brahimi-Horn MC, Chiche J and Pouyssegur J: Hypoxia and cancer. J Mol Med 85: 1301-1307, 2007.

19. Brahimi-Horn MC, Chiche J and Pouyssegur J: Hypoxia signalling controls metabolic demand. Curr Opin Cell Biol 19: 223-229, 2007.

20. Neufeld G, Cohen T, Gengrinovitch S and Poltorak Z: Vascular endothelial growth factor (VEGF) and its receptors. FASEB J 13: 9-22, 1999.

21. Hirakawa S, Kodama S, Kunstfeld R, Kajiya K, Brown LF and Detmar M: VEGF-A induces tumor and sentinel lymph node lymphangiogenesis and promotes lymphatic metastasis. J Exp Med 201: 1089-1099, 2005.

22. Halin C, Tobler NE, Vigl B, Brown LF and Detmar M: VEGF-A produced by chronically inflamed tissue induces lymphangiogenesis in draining lymph nodes. Blood 110: 3158-3167, 2007.

23. Ballweber E, Hannappel E, Huff T, et al: Polymerisation of chemically cross-linked actin:thymosin betaß4) complex to filamentous actin: alteration in helical parameters and visualisation of thymosin betaß4) binding on F-actin. J Mol Biol 315: 613-625, 2002.

24. Sanders MC, Goldstein AL and Wang YL: Thymosin beta 4 (Fx peptide) is a potent regulator of actin polymerization in living cells. Proc Natl Acad Sci USA 89: 4678-4682, 1992.

25. Cha HJ, Jeong MJ and Kleinman HK: Role of thymosin beta4 in tumor metastasis and angiogenesis. J Natl Cancer Inst 95: 1674-1680, 2003.

26. Koutrafouri V, Leondiadis L, Avgoustakis K, et al: Effect of thymosin peptides on the chick chorioallantoic membrane angiogenesis model. Biochim Biophys Acta 1568: 60-66, 2001.

27. Malinda KM, Sidhu GS, Mani H, et al: Thymosin beta4 accelerates wound healing. J Invest Dermatol 113: 364-368, 1999.

28. Philp D, Badamchian M, Scheremeta B, Nguyen M, Goldstein AL and Kleinman HK: Thymosin beta 4 and a synthetic peptide containing its actin-binding domain promote dermal wound repair in $\mathrm{db} / \mathrm{db}$ diabetic mice and in aged mice. Wound Repair Regen 11: 19-24, 2003.

29. Badamchian M, Fagarasan MO, Danner RL, Suffredini AF, Damavandy $\mathrm{H}$ and Goldstein AL: Thymosin betaß4) reduces lethality and down-regulates inflammatory mediators in endotoxin-induced septic shock. Int Immunopharmacol 3: 1225-1233, 2003.

30. Sosne G, Szliter EA, Barrett R, Kernacki KA, Kleinman H and Hazlett LD: Thymosin beta 4 promotes corneal wound healing and decreases inflammation in vivo following alkali injury. Exp Eye Res 74: 293-299, 2002.

31. Young JD, Lawrence AJ, MacLean AG, et al: Thymosin beta 4 sulfoxide is an anti-inflammatory agent generated by monocytes in the presence of glucocorticoids. Nat Med 5: 1424-1427, 1999.

32. Bock-Marquette I, Saxena A, White MD, Dimaio JM and Srivastava D: Thymosin beta4 activates integrin-linked kinase and promotes cardiac cell migration, survival and cardiac repair. Nature 432: 466-472, 2004.

33. Wang WS, Chen PM, Hsiao HL, Ju SY and Su Y: Overexpression of the thymosin beta- 4 gene is associated with malignant progression of SW480 colon cancer cells. Oncogene 22: 3297-3306, 2003 .

34. Wang WS, Chen PM, Hsiao HL, Wang HS, Liang WY and $\mathrm{Su}$ Y: Overexpression of the thymosin beta- 4 gene is associated with increased invasion of SW480 colon carcinoma cells and the distant metastasis of human colorectal carcinoma. Oncogene 23: 6666-6671, 2004.

35. Huang HC, Hu CH, Tang MC, Wang WS, Chen PM and Su Y: Thymosin beta4 triggers an epithelial-mesenchymal transition in colorectal carcinoma by upregulating integrin-linked kinase. Oncogene 26: 2781-2790, 2007. 
36. Wittekind C, Compton CC, Greene FL and Sobin LH: TNM residual tumor classification revisited. Cancer 94: 2511-2516, 2002.

37. Boden D, Pusch O, Silbermann R, Lee F, Tucker L and Ramratnam B: Enhanced gene silencing of HIV-1 specific siRNA using microRNA designed hairpins. Nucleic Acids Res 32: 1154-1158, 2004

38. Dull T, Zufferey R, Kelly M, et al: A third-generation lentivirus vector with a conditional packaging system. J Virol 72: 8463-8471, 1998.

39. Follenzi A, Ailles LE, Bakovic S, Geuna M and Naldini L: Gene transfer by lentiviral vectors is limited by nuclear translocation and rescued by HIV-1 pol sequences. Nat Genet 25 : 217-222, 2000

40. Oh JM, Ryoo IJ, Yang Y, Kim HS, Yang KH and Moon EY: Hypoxia-inducible transcription factor (HIF)- 1 alpha stabilization by actin-sequestering protein, thymosin beta- 4 (TB4) in Hela cervical tumor cells. Cancer Lett 264: 29-35, 2008.

41. Schoppmann SF, Fenzl A, Schindl M, et al: Hypoxia inducible factor-1alpha correlates with VEGF-C expression and lymphangiogenesis in breast cancer. Breast Cancer Res Treat 99: 135$141,2006$.

42. Achen MG and Stacker SA: Molecular control of lymphatic metastasis. Ann N Y Acad Sci 1131: 225-234, 2008.

43. Eccles S, Paon L and Sleeman J: Lymphatic metastasis in breast cancer: importance and new insights into cellular and molecular mechanisms. Clin Exp Metastasis 24: 619-636, 2007.
44. Kimbro KS and Simons JW: Hypoxia-inducible factor-1 in human breast and prostate cancer. Endocr Relat Cancer 13: 739-749, 2006.

45. Yamamoto T, Gotoh M, Kitajima M and Hirohashi S: Thymosin beta-4 expression is correlated with metastatic capacity of colorectal carcinomas. Biochem Biophys Res Commun 193: 706-710, 1993.

46. Larsson LI and Holck S: Occurrence of thymosin beta4 in human breast cancer cells and in other cell types of the tumor microenvironment. Hum Pathol 38: 114-119, 2007.

47. Cao R, Bjorndahl MA, Religa P, et al: PDGF-BB induces intratumoral lymphangiogenesis and promotes lymphatic metastasis. Cancer Cell 6: 333-345, 2004.

48. Whitehurst B, Flister MJ, Bagaitkar J, et al: Anti-VEGF-A therapy reduces lymphatic vessel density and expression of VEGFR-3 in an orthotopic breast tumor model. Int J Cancer 121: 2181-2191, 2007

49. Kajiya K, Hirakawa S, Ma B, Drinnenberg I and Detmar M: Hepatocyte growth factor promotes lymphatic vessel formation and function. EMBO J 24: 2885-2895, 2005.

50. van der Schaft DW, Pauwels P, Hulsmans S, Zimmermann M, van de Poll-Franse LV and Griffioen AW: Absence of lymphangiogenesis in ductal breast cancer at the primary tumor site. Cancer Lett 254: 128-136, 2007. 